\title{
Energy efficiency of timber construction joint with wooden screw
}

\author{
Ivan Inzhutov ${ }^{1}$, Sergey Amelchugov ${ }^{1}$, Rashit Nazirov ${ }^{1}$, Marina Perkova ${ }^{1}$, Christina \\ Rudyak $^{1}$, and Ada Baltinate ${ }^{1, *}$ \\ ${ }^{1}$ Siberian Federal University, 82 Svobodny pr., Krasnoyarsk, 660041, Russia
}

\begin{abstract}
The topicality of studied subject is based on inappropriate usage of different materials in wooden structures, since using metal joint in wooden construction leads to reduction of construction working life cycle. In this regard, a study of several options for wooden screw carving was conducted in order to determine the most appropriate one (screw). There are several different types of carving, such as: trapezoidal, triangular, rectangular, etc. The most appropriate ones are trapezoidal and triangularsection threads for wooden screws. The effectiveness of a wooden screw thread was determined from the conditions (capacity) of shear fracture and bearing stress. After analyzing the results of calculations of the specific capacity for shear fracture and bearing stress, it can be concluded that the value of specific bearing capacity for shear fracture is less than the value of bearing stress by $1.3 \%$. Therefore, a further comparison of the trapezoidal thread and the triangular cross-section will proceed from the spalling conditions. It has been found that the most effective thread is a triangular cross-section. Based on the results of calculations, a mathematical model has been established that describes the dependence of the carrying capacity on the screw diameter.
\end{abstract}

\section{Introduction}

In buildings made of wood, one of the elements of heat loss are metal compounds which lead to in energy consumption increase.

There are several types of joints: pin, glutinous, connections on the mechanical joints (tree nail, spline, etc.). The most widely spread is treenail connections among compounds on the mechanical joints.

At least a quarter of the cylindrical tree nail must be made in the form of bolts and studs that would compress the connection. Cylindrical tree nails made of steel, aluminum, fiberglass and hard wood (oak, hornbeam, birch, etc.) were used in construction practice [1]. However, according to many designers' preference in wooden structures should be given to the latter for the following reasons [2]:

- uniformity with the main building material, resulting in uniform shrinkage of the resulting structure;

\footnotetext{
* Corresponding author: Dero-gai@mail.ru
} 
- no deformation of the walls of wooden buildings which is an obvious consequence of uniform shrinkage;

- the impossibility of formation of cold bridge (when using pins made of metal are often at the location of the fastener forms a cold bridge reducing the comfort in the building and increases the value of the cost of heating the building);

- resistance to changes in temperature and humidity parameters of the environment.

There is no information on the calculation thread with tree nail in the scientific technical and regulatory Russian literature. In this regard, we conducted a study of several types of carving on wooden screws.

The purpose of the article is to establish effective thread parameters for wooden screws.

Objectives are to investigate and analyze wood screw connections in constructions.

\section{Object of study}

There are several different types of thread, such as trapezoidal, triangular, rectangular, etc. The most appropriate for wood screws are trapezoidal and triangular threads.

The object of the research in this article is a trapezoidal thread and the thread of triangular section on the wood screws.

Screws with threaded cutting are made of hard wood (birch, beech, oak, maple, etc.).

For most indicators birch is not inferior to beech. Coefficients of birch wood quality on compression along the fibers, bending, specific work in shock bending is much higher than for beech wood. And only at the end of the hardness and chipping along the grain the birch is slightly inferior to the beech [3]. In the paper the calculation was carried out for wood screws made of birch.

The maximum possible value of shrinkage and swelling of wood based on the class of operating conditions, is $3.4 \mathrm{~mm}$ and the coefficient of thermal expansion this should be taken into account in the design and operation. It is also necessary to take into account the coefficient of thermal expansion which depends on the moisture content in the wood $[4,5$, $6]$.

To identify the most effective type of thread on a wooden workpiece we conducted a numerical study of the stress-strain state. As a result, has been established that such is the thread of the triangular section. Table 1 shows the parameters of the thread.

Table 1. Options of thread triangular cross-section.

\begin{tabular}{|c|c|c|c|c|c|}
\hline $\begin{array}{c}\text { Screw } \\
\text { diameter D, } \\
\mathbf{m m}\end{array}$ & $\begin{array}{c}\text { Screw } \\
\text { diameter } \\
\mathbf{d}, \mathbf{m m}\end{array}$ & $\begin{array}{c}\text { Step } \\
\mathbf{( T )} \\
\mathbf{m m}\end{array}$ & $\begin{array}{c}\text { The length of } \\
\text { the plane of } \\
\text { shear Lck mm }\end{array}$ & $\begin{array}{c}\text { Height h, } \\
\mathbf{m m}\end{array}$ & Angle $\boldsymbol{\alpha}$, degree \\
\hline 12 & 8 & 4 & 4 & 2 & $60,65,70,75,80$ \\
\hline 14 & 10 & 4 & 4 & 2 & $60,65,70,75,80$ \\
\hline 16 & 12 & 4 & 4 & 2 & $60,65,70,75,80$ \\
\hline 18 & 12 & 5 & 5 & 3 & $60,65,70,75,80$ \\
\hline 20 & 14 & 5 & 5 & 3 & $60,65,70,75,80$ \\
\hline 22 & 16 & 5 & 5 & 3 & $60,65,70,75,80$ \\
\hline 24 & 16 & 6 & 6 & 4 & $60,65,70,75,80$ \\
\hline 26 & 18 & 6 & 6 & 4 & $60,65,70,75,80$ \\
\hline 28 & 20 & 6 & 6 & 4 & $60,65,70,75,80$ \\
\hline 30 & 20 & 7 & 7 & 5 & $60,65,70,75,80$ \\
\hline 32 & 22 & 7 & 7 & 5 & $60,65,70,75,80$ \\
\hline 34 & 24 & 7 & 7 & 5 & $60,65,70,75,80$ \\
\hline 36 & 24 & 8 & 8 & 6 & $60,65,70,75,80$ \\
\hline 38 & 26 & 8 & 8 & 6 & $60,65,70,75,80$ \\
\hline
\end{tabular}




\begin{tabular}{|l|l|l|l|l|l|}
\hline 40 & 28 & 8 & 8 & 6 & $60,65,70,75,80$ \\
\hline 42 & 28 & 9 & 9 & 7 & $60,65,70,75,80$ \\
\hline 44 & 30 & 9 & 9 & 7 & $60,65,70,75,80$ \\
\hline 46 & 32 & 9 & 9 & 7 & $60,65,70,75,80$ \\
\hline 48 & 32 & 10 & 10 & 8 & $60,65,70,75,80$ \\
\hline 50 & 34 & 10 & 10 & 8 & $60,65,70,75,80$ \\
\hline 52 & 36 & 10 & 10 & 8 & $60,65,70,75,80$ \\
\hline
\end{tabular}

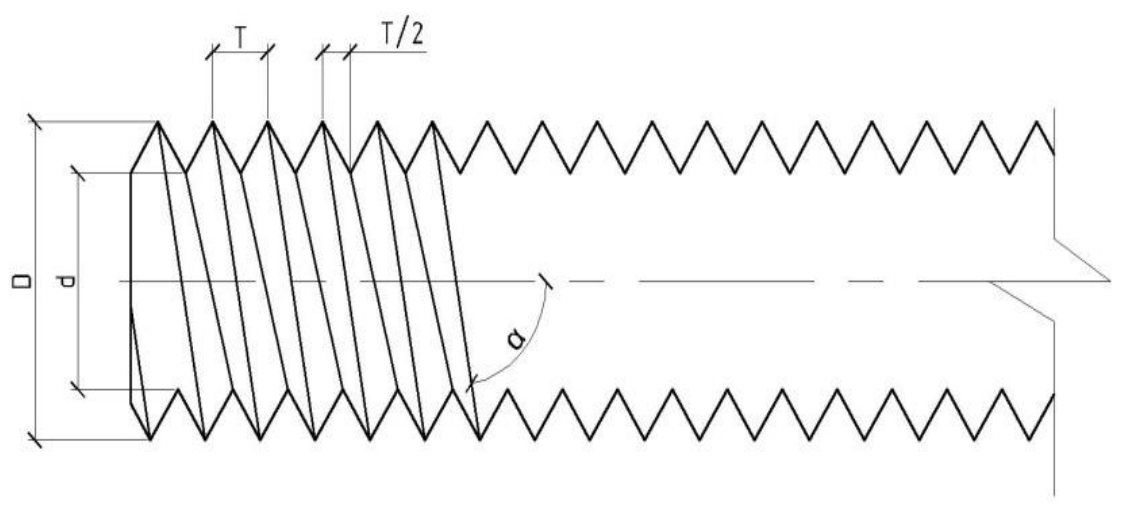

Fig. 1. Parameters of the thread denote.

\section{Calculation method}

The specific carrying capacity of shear fracture joints reduced to one centimeter of screw length was calculated according to the formula:

$$
\mathrm{T}=\mathrm{R}_{\mathrm{ck}}^{\mathrm{cp}} \times \mathrm{F}_{\mathrm{ck}}
$$

$\mathrm{F}_{\mathrm{ck}}$ - effective shear fracture area;

$\mathrm{R}_{\mathrm{ck}}^{\mathrm{cp}}$ - effective average of the spalling area of wood resistance;

The calculated area of spalling was defined as the area of the base of one tooth on the length of the coil.

$$
\mathrm{F}_{\mathrm{ck}}=\mathrm{L}_{\mathrm{ck}} \times\left(\delta_{\mathrm{d}} \times \mathrm{m}_{\mathrm{d}}\right) \text {, }
$$

$\mathrm{L}_{\mathrm{ck}}$ - effective length of the shear fracture plane; $\delta_{d}-$ length of the inner circumference of the screw; $\mathrm{m}_{\mathrm{d}}$ - coefficient depending on $\alpha$ (table 2 ); $\alpha$ - inclination of the thread to the axis of the screw.

Table 2. Coefficient $\mathrm{m}_{\mathrm{d}}$.

\begin{tabular}{c|c|c|c|c|c|}
\hline coefficient & $\boldsymbol{\alpha}=\mathbf{6 0}^{\circ}$ & $\boldsymbol{\alpha}=\mathbf{6 5}^{\circ}$ & $\boldsymbol{\alpha}=\mathbf{7 0}^{\circ}$ & $\boldsymbol{\alpha}=\mathbf{7 5}$ & $\boldsymbol{\alpha}=\mathbf{8 0}^{\circ}$ \\
\hline $\mathrm{m}_{\mathrm{d}}$ & 1.067 & 1.054 & 1.04 & 1.027 & 1.013 \\
\hline & $\mathrm{R}_{\mathrm{ck}}^{\mathrm{cp}}=\frac{\mathrm{R}_{\mathrm{ck}}}{1+\beta \times \frac{\mathrm{L}_{\mathrm{ck}}}{\mathrm{e}}}$,
\end{tabular}

$R_{c k}$ - effective resistance to shear fracture along the fibers; $\beta$ - coefficient taken to be 0.125 ;

$\mathrm{L}_{\mathrm{ck}}$ - effective length of the shear plane; $\mathrm{e}$ - moment arm shear fracture.

Specific bearing capacity bearing stress nut:

$$
\mathrm{T}=\mathrm{R}_{\mathrm{cm} \alpha} \times \mathrm{F}_{\mathrm{cm}}
$$


$\mathrm{F}_{\mathrm{cm}}$ - effective bearing stress area; $\mathrm{R}_{\mathrm{cm} \alpha^{-}}$calculated average area of collapse wood resistance;

Estimated area of the collapse was calculated as the area of the base of one tooth on the length of the thread.

$$
\mathrm{F}_{\mathrm{cm}}=\left(\mathrm{L}_{\mathrm{cm}} \times \mathrm{m}_{\mathrm{x}}\right) \times\left[\left(\delta_{\mathrm{d}} \times \mathrm{m}_{\mathrm{d}}\right) \times \mathrm{m}_{\mathrm{y}}\right],
$$

$\mathrm{L}_{\mathrm{cm}}$ - effective length of the bearing stress plane; $\delta_{\mathrm{d}}$ - the length of the inner circumference of the nu;

$\mathrm{m}_{\mathrm{x}}, \mathrm{m}_{\mathrm{y}}-$ coefficients taking into account the amount of wood deformation $(0.5 \mathrm{~mm})$ for normal operating conditions where: $\mathrm{m}_{\mathrm{x}}=0.95 ; \mathrm{m}_{\mathrm{y}}=1.1$

\section{Research result}

For analysis convenience the results are summarized in Table 3 and approximated (Figure 2).

The estimated specific bearing capacity is taken as the smallest of the conditions for shear fracture and bearing stress

Table 3. The specific bearing capacity of the screw from the birch working for shear fracture.

\begin{tabular}{|c|c|c|c|c|c|}
\hline $\begin{array}{c}\text { Diamet } \\
\text { r, mm }\end{array}$ & $\begin{array}{c}\text { Specific } \\
\text { load- } \\
\text { bearing } \\
\text { capacity of } \\
\text { T-joint for } \\
\text { threads } \\
\text { with angle } \\
\boldsymbol{\alpha}_{\mathbf{6 0 0}}^{\circ}\end{array}$ & $\begin{array}{c}\text { Specific load- } \\
\text { bearing } \\
\text { capacity of T- } \\
\text { joint for } \\
\text { threads with } \\
\text { angle } \boldsymbol{\alpha}=\mathbf{6 5}^{\circ}\end{array}$ & $\begin{array}{c}\text { Specific load- } \\
\text { bearing } \\
\text { capacity of } \\
\text { T-joint for } \\
\text { threads with } \\
\text { angle } \boldsymbol{\alpha}=\mathbf{7 0}^{\circ}\end{array}$ & $\begin{array}{c}\text { Specific load- } \\
\text { bearing } \\
\text { capacity of T- } \\
\text { joint for } \\
\text { threads with } \\
\text { angle } \boldsymbol{\alpha}=\mathbf{7 5}^{\circ}\end{array}$ & $\begin{array}{c}\text { Specific } \\
\text { load- } \\
\text { bearing } \\
\text { capacity of } \\
\text { T-joint for } \\
\text { threads } \\
\text { with angle } \\
\boldsymbol{\alpha}=\mathbf{8 0}^{\circ}\end{array}$ \\
\hline 12 & 0.0017 & 0.0017 & 0.0017 & 0.0017 & 0.0016 \\
\hline 14 & 0.0022 & 0.0022 & 0.0021 & 0.0021 & 0.0021 \\
\hline 16 & 0.0026 & 0.0026 & 0.0026 & 0.0025 & 0.0025 \\
\hline 18 & 0.0026 & 0.0026 & 0.0026 & 0.0025 & 0.0025 \\
\hline 20 & 0.0031 & 0.0030 & 0.0030 & 0.0030 & 0.0029 \\
\hline 22 & 0.0035 & 0.0035 & 0.0035 & 0.0034 & 0.0034 \\
\hline 24 & 0.0035 & 0.0035 & 0.0034 & 0.0034 & 0.0033 \\
\hline 26 & 0.0040 & 0.0039 & 0.0039 & 0.0038 & 0.0038 \\
\hline 28 & 0.0044 & 0.0044 & 0.0043 & 0.0043 & 0.0042 \\
\hline 30 & 0.0044 & 0.0044 & 0.0043 & 0.0043 & 0.0042 \\
\hline 32 & 0.0049 & 0.0048 & 0.0048 & 0.0047 & 0.0046 \\
\hline 34 & 0.0053 & 0.0053 & 0.0052 & 0.0051 & 0.0051 \\
\hline 36 & 0.0053 & 0.0052 & 0.0052 & 0.0051 & 0.0050 \\
\hline 38 & 0.0058 & 0.0057 & 0.0056 & 0.0056 & 0.0055 \\
\hline 40 & 0.0062 & 0.0062 & 0.0061 & 0.0060 & 0.0059 \\
\hline 42 & 0.0062 & 0.0061 & 0.0061 & 0.0060 & 0.0059 \\
\hline 44 & 0.0067 & 0.0066 & 0.0065 & 0.0064 & 0.0063 \\
\hline 46 & 0.0071 & 0.0070 & 0.0070 & 0.0069 & 0.0068 \\
\hline 48 & 0.0071 & 0.0070 & 0.0069 & 0.0068 & 0.0068 \\
\hline 50 & 0.0076 & 0.0075 & 0.0074 & 0.0073 & 0.0072 \\
\hline 52 & 0.0080 & 0.0079 & 0.0078 & 0.0077 & 0.0076 \\
\hline & & & & & \\
\hline
\end{tabular}


Table 4. The specific bearing capacity of the screw from the birch working for bearing stress.

\begin{tabular}{|c|c|c|c|c|c|}
\hline $\begin{array}{c}\text { Diametr, } \\
\text { mm }\end{array}$ & $\begin{array}{c}\text { Specific } \\
\text { load-bearing } \\
\text { capacity of } \\
\text { T-joint for } \\
\text { threads with } \\
\text { angle } \alpha= \\
60^{\circ}\end{array}$ & $\begin{array}{c}\text { Specific load- } \\
\text { bearing } \\
\text { capacity of T- } \\
\text { joint for } \\
\text { threads with } \\
\text { angle } \alpha=65^{\circ}\end{array}$ & $\begin{array}{c}\text { Specific load- } \\
\text { bearing } \\
\text { capacity of T- } \\
\text { joint for } \\
\text { threads with } \\
\text { angle } \alpha=70^{\circ}\end{array}$ & $\begin{array}{c}\text { Specific load- } \\
\text { bearing capacity } \\
\text { of T-joint for } \\
\text { threads with } \\
\text { angle } \alpha=75^{\circ}\end{array}$ & $\begin{array}{c}\text { Specific } \\
\text { load-bearing } \\
\text { capacity of } \\
\text { T-joint for } \\
\text { threads with } \\
\text { angle } \alpha= \\
80^{\circ}\end{array}$ \\
\hline 12 & 0.0018 & 0.0018 & 0.0017 & 0.0017 & 0.0017 \\
\hline 14 & 0.0022 & 0.0022 & 0.0022 & 0.0022 & 0.0021 \\
\hline 16 & 0.0027 & 0.0027 & 0.0026 & 0.0026 & 0.0026 \\
\hline 18 & 0.0027 & 0.0027 & 0.0026 & 0.0026 & 0.0026 \\
\hline 20 & 0.0031 & 0.0031 & 0.0031 & 0.0030 & 0.0030 \\
\hline 22 & 0.0036 & 0.0035 & 0.0035 & 0.0035 & 0.0034 \\
\hline 24 & 0.0036 & 0.0035 & 0.0035 & 0.0035 & 0.0034 \\
\hline 26 & 0.0040 & 0.0040 & 0.0039 & 0.0039 & 0.0038 \\
\hline 28 & 0.0045 & 0.0044 & 0.0044 & 0.0043 & 0.0043 \\
\hline 30 & 0.0045 & 0.0044 & 0.0044 & 0.0043 & 0.0043 \\
\hline 32 & 0.0049 & 0.0049 & 0.0048 & 0.0047 & 0.0047 \\
\hline 34 & 0.0054 & 0.0053 & 0.0052 & 0.0052 & 0.0051 \\
\hline 36 & 0.0054 & 0.0053 & 0.0052 & 0.0052 & 0.0051 \\
\hline 38 & 0.0058 & 0.0058 & 0.0057 & 0.0056 & 0.0055 \\
\hline 40 & 0.0063 & 0.0062 & 0.0061 & 0.0060 & 0.0060 \\
\hline 42 & 0.0063 & 0.0062 & 0.0061 & 0.0060 & 0.0060 \\
\hline 44 & 0.0067 & 0.0066 & 0.0066 & 0.0065 & 0.0064 \\
\hline 46 & 0.0072 & 0.0071 & 0.0070 & 0.0069 & 0.0068 \\
\hline 48 & 0.0072 & 0.0071 & 0.0070 & 0.0069 & 0.0068 \\
\hline 50 & 0.0076 & 0.0075 & 0.0074 & 0.0073 & 0.0072 \\
\hline 52 & 0.0081 & 0.0080 & 0.0079 & 0.0078 & 0.0077 \\
\hline
\end{tabular}

After analyzing the results of calculating the specific capacity for shear fracture and bearing stress it can be concluded that the value of specific bearing capacity for shear fracture is less than the value of bearing stress by $1.3 \%$, therefore a further comparison of the trapezoidal thread and the triangular cross-section will proceed from the splitting conditions.

According to the results given in table 3 it can be seen that with a decrease in the inclination of the thread to the axis of the screw the specific bearing capacity increases when working on shear fracture. This is due to the fact that thanks to an increase in the coefficient $m_{d}$ of the $\alpha$-dependent inclination of the thread to the screw axis the shear plane increases which leads to an increase in the specific bearing capacity for shear fracture.

Figure 2 shows a specific bearing capacity-screw diameter diagram. 


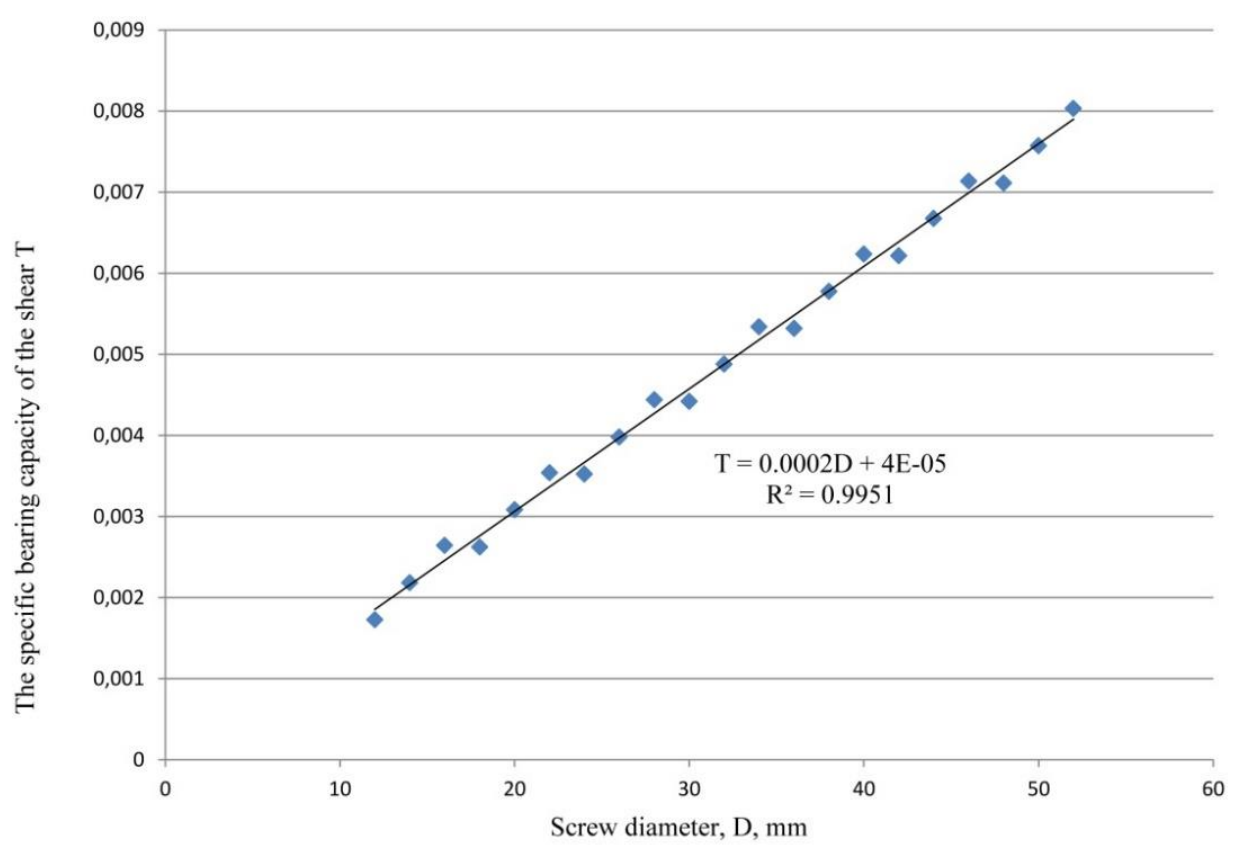

Fig. 2. Specific shear fracture capacity-screw diameter diagram; $\mathrm{R}^{2}$ - the reliability coefficient of the fitting model.

Computational mathematical model has been derived from approximation of the obtained points.

The axial load over the threads of the nut is unevenly distributed due to the unfavorable combination of screw and nut deformations (the turns in the most stretched part of the screw interact with the turns of the most compressed part of the nut) [8].

The statically undefined problem of load distribution over turns [9] of a rectangular thread nut with 10 turns was solved by prof. NOT. Zhukovsky in 1902, later similar decisions were obtained abroad by E. Jacquet and L. Madushka $[10,11]$. In the future this decision was confirmed by numerous experimental studies. It was established that in a standard fastening nut with six turns the first most loaded turn accounts for $\approx 52 \%$ of the total load, the second $-25 \%$, the third $-12 \%$, the fourth $-6 \%$, the fifth $-3 \%$, the sixth $2 \%$. Taking into account the uneven distribution of the load over the threads the height of the nut should be taken by the number of turns $\mathrm{z} \leq 8[8,12,13]$.

\section{Technological features}

Screws should be made of hard wood (birch or beech) [7]. Intergrown knots are allowed if they are healthy on the threaded part of the screw no more than one with a diameter of 7 $\mathrm{mm}$ or no more than two with a diameter of $3 \mathrm{~mm}$ with distance between them of at least 80 $\mathrm{mm}$; at the head of the screw with a total diameter up to $20 \mathrm{~mm}$. knots are not allowed in the transition head to cut part of the screw.

Blanks at the time of manufacture of screws should have a moisture content of not more than $18 \%$.

A slight slope of the fibers (up to $5 \%$ ) slightly affects the strength of the parts (tensile strength in static bending is reduced by 5-6\%). With a significant inclination of the fibers (about $12 \%$ ) the tensile strength at static bending is reduced by $10-12 \%$ at natural and by $20-21 \%$ at artificial inclination of the fibers. The inclination of fibres increases durability of 
wood at spalling but complicates its mechanical processing and reduces ability to a bend. Timber with tangential fiber slope is characterized by increased longitudinal shrinkage and warping [4].

There are several ways of applying screw thread on a wooden element (milling, lathe).

Not purely drilled hole for wooden screws will not allow to get a good thread in it and the screw may break when screwed.

Depending on the direction of movement of the tool (cutter) in relation to the arrangement of the processed wood fibers there are three main ways of cutting: end where cutting plane is perpendicular to the fibers, the chip is chipped and consists of loosely connected or unbound individual elements; longitudinal where cutting direction coincides with the direction of the fibers, the chip is formed in the form of a thin tape sometimes it breaks diverging into parts; transverse when the cutter moves in the plane of the fibers perpendicular to their length, the chip elements are loosely connected.

Under the same conditions, the maximum cutting resistance is observed in the case of end cutting and the minimum in the transverse one.

A hollow tap is used for thread cutting in drilled holes for wooden screws. It consists of a cutting head with three cutting teeth, a hollow cylindrical rod with a recess at the end for fixing a square shank with the help of which the tap is installed in the chuck of the power head of the machine or electric drill.

From the end of the tap the cutting teeth are sharpened at an angle of $120^{\circ}$ to a depth equal to the cutting step; the front angle must be maintained within $8-10^{\circ}$.

\section{Recommendations for design of screw connections}

Screw connections refer to connections on mechanical joints. They provide the screws usage as shear bonds when they work mainly on the cut and the joints are spacer.

The main conditions for the reliability of the used compounds should be the quality control of screws and connected elements as well as the applied methods of their calculation and test methods of compounds confirming the results of calculations.

The main design parameters of screw connections which should be taken into account in the design are: the estimated size of the screws, the size of the landing holes, as well as regulated schemes of their arrangement.

The diameter of wooden screws with trapezoidal and triangular thread is recommended to take in the range from 12 to $52 \mathrm{~mm}$.

The diameter of the landing holes should be greater than the diameter of the screw from 0.5 to $3.4 \mathrm{~mm}$ depending on the size of the workpiece and the type of sawing (radial or tangent) $[14,15]$. The basic sizes of arrangement of screws in landing apertures correspond: step, distance between rows and the minimum distance of an axis of the screw to edge of the connected element as a rule are proved experimentally-theoretical methods and regulated by standards for the purpose of premature destruction prevention of connections at their work from chipping or rupture of wood.

Screws may be used primarily for various types of joints of elements made of solid spruce wood, laminated wood, hard wood, etc., for rallying in the transverse direction of the structural elements, splicing elements in the longitudinal direction. According to the nature of the acting forces and the number of shear joints (sections) between the mating elements the following schemes of connection work are distinguished:

- symmetrical — double-shear and multiple cuts joints;

- steel - single cut, double- cut and multiple cuts joints. 


\section{Conclusion}

According to the investigated variants of the thread for chipping the most effective is a triangular thread with an angle of inclination to the axis of the screw $60^{\circ}$. This is explained by the fact that the thread of the triangular cross-section has a larger chipping area and as a result the chipping load is distributed more evenly.

In accordance with the results of calculations we revealed that the determining factor for screw connections is the work on chipping. From the results of calculations a mathematical model describing the dependence of the bearing capacity on the diameter of the screw is established.

\section{References}

1. F. Matthias, B.H Joachim, Springer, Netherlands 77 (2014)

2. UKTFA, Engineered wood products and an introduction to timber structural systems (The Structural Engineer, 2013)

3. O. Allegretti, L. Travan, R. Cividini, Proc. of European Drying Group Conference 7 (2009)

4. J. Tomad, S. Jantawee, W. Preechatiwong, N. Matan, Holz als Roh- und Werkstoff 76, 9 (2017)

5. G. Goli, F. Becherini, M. Concetta Di Tuccio, A. Bernardi, M. Fioravanti, J. Wood Sci. 64, 4 (2019)

6. G. Almeida, R. Hernandez, Wood Mater Sci Eng E 2, 33 (2007)

7. B. Cihad Bal, Conference Paper 223 (2016)

8. S.K. Sundaram, R.V. Prakash, Proceedings of the ASME 2015 IMECE 266 (2015)

9. Z.D. Duan, J.F. Gao, T.M. Su, Advanced Materials Research E 148, 99 (2011)

10. X. Chen, N. Noda, M.A. Wahab, Y. Akaishi, Y. Sano, Y. Takase, G. Fekete, Acta Polytechnica 12, 8 (2015)

11. O. Tor, X. Yu, J. Zhang, Journal of the Society of Wood Science and Technology 47, $126(2015)$

12. N.L. Pedersen, The Journal of Strain Analysis for Engineering Design 48, 26 (2013)

13. N.L. Pedersen, Archive of Applied Mechanics 83, 194 (2013)

14. C.A. Eckelman, Purdue University Department of Forestry \&Natural Resources (West Lafayette, 2010)

15. B. Clair, J. Alteyrac, A. Gronvold, J. Espejo, B. Chanson, T. Alméras, Annals of Forest Science 70, 801 (2013) 